\title{
Pão \& Fonema: um grito épico na literatura africana
}

\author{
Tatiana de F. Alves Moysés*
}

\begin{abstract}
Resumo: Parte da literatura africana estabelece laços Abstract: Part of the African literature establishes vivos e explícitos com a épica; no entanto, isso não vivid and explicit bonds with epic. However, it does significa que se trata de uma mera reprodução desse not mean that it is a mere reproduction of this genre. As gênero. Como se sabe, para se transmitir é necessário one knows, in order to transmit it is necessary that a que um conceito passe por transformações. Nesse concept passes through transformations. In this sense, sentido, para reabilitar o gênero épico na literatura do for rehabilitating the epic genre in the $20^{\text {th }}$ century século XX, os autores africanos fizeram adaptações que literature, African writers made adaptations that could correspondessem ao seu tempo e espaço. Isto posto, correspond to their time and space. Therefore, this esse trabalho tem o intuito de verificar como Corsino work has the intention of verifying how Corsino Fortes Fortes constrói a obra Pão \& Fonema, ora se constructs the piece Pão \& Fonema, sometimes aproximando, ora se afastando da épica clássica. approximating, sometimes deviating from the classic epic.
\end{abstract}

Palavras-chave: Epopéia; Literatura Africana; Keywords: Epic; African literature; Modernity Modernidade

O continente africano reúne em sua extensão territorial diferenças lingüísticas, culturais, geográficas, econômicas e religiosas. Tal diversidade intensificou-se na medida em que seus habitantes entraram em contato com a cultura imposta pela Europa. No entanto, existe um aspecto comum que perpassa grande parte da trajetória desses países: a violência da colonização.

A partir da análise do processo de colonização nota-se que, no sistema colonial, implantado pelo ocidente, a colônia existia em função e para a metrópole. Sua produção somente era válida quando possibilitava lucros elevados aos comerciantes metropolitanos, detentores do monopólio sobre o comércio de importação e de exportação. Percebe-se então que o objetivo dos Estados colonizadores era submeter as colônias a todo tipo de exploração, a fim de torná-la um projeto econômico viável. Para que tal intento tivesse êxito, além da força bruta, os europeus optaram por empregar recursos que garantissem sua dominação efetiva, dentre eles destaca-se a tentativa de destruir a cultura do colonizado, destituí-lo de seus objetos de culto e, sobretudo, destruir sua língua. De acordo com Pires Laranjeira (1995),

\footnotetext{
* Mestranda do Programa de Literatura Portuguesa. Departamento de Letras Clássicas e Vernáculas. Universidade de São Paulo. E-mail: alvesmoyses@hotmail.com
} 
em A Negritude Africana de Língua Portuguesa, na sociedade colonial, tentou-se silenciar qualquer resquício da identidade do colonizado, principalmente, no que concernisse à língua:

A classe dominante colonial tende a impor a si e aos outros o mesmo sistema cultural e lingüístico, o código ou códigos que acha legítimo(s). Os outros usam-se ou, como diz RossiLandi, calam-se. Escrever, no quadro da ideologia da dominação colonial, acontece de acordo com o código aceite para uso e benefício do sistema vigente (sistema político, sistema cultural, sistema da língua-padrão de Lisboa ou do padrão-colonial). (LARANJEIRA, 1995, p.173)

É evidente que a atitude repressora dessa classe dominante desencadeou um movimento de revolta e resistência, que culminou no processo de independência dos povos subjugados. Na África, em geral, a luta pela libertação se dividiu basicamente em duas vertentes: a luta armada e o combate através da literatura. Os intelectuais africanos além de atuarem como soldados nas batalhas pró-independência, começaram a produzir uma literatura de afirmação, cujo objetivo era resgatar as tradições do seu povo.

Com efeito, a literatura que estava a surgir tinha uma função bastante complexa, já que tomou para si o encargo de retomar as histórias africanas, até então contadas apenas pelos colonizadores. Planejava-se, portanto, fazer um resgate sistemático dos elementos da tradição que foram suplantados pelo colonialismo. Além disso, os intelectuais desse momento incumbiram-se da tarefa de construir uma nova nação. Nesse sentido, fazia-se necessário escrever um texto no presente que resgatasse o passado e ao mesmo tempo idealizasse o futuro. Isto posto, pode-se afirmar que a literatura pretendia contribuir para a formação da identidade de um povo.

De fato, os intelectuais africanos tinham o intuito de libertar-se das marcas deixadas pelos colonizadores. Contudo, viram-se envolvidos em uma contradição, pois na medida em que objetivavam consolidar a nacionalidade através da literatura, retomaram um aspecto que já havia sido empregado pela tradição clássica européia: a épica.

Segundo Ana Madalfa Leite (1987), embora haja um espaço temporal significativo entre os escritores épicos clássicos e os africanos do século XX, pode-se afirmar que parte da literatura produzida na África, no processo de luta armada pró-libertação, é marcada por uma discursividade épica:

Formalmente, os poemas épicos africanos aglomeram vários gêneros, microgéneros ditirâmbicos, canções populares, amplificando-se e orientando a matéria histórica para o mito. Segundo Moussa Sow, se o conto ou outras variantes asseguram uma função de informação na literatura oral, e se por outro lado o mito explica as origens, a epopéia realiza tudo isso em simultaneo: é gênero político que usa todas as funções para manter vivas as imagens de uma identidade comunitária e nacional. (LEITE, 1987, p.38) 
A literatura africana estabelece laços vivos e explícitos com a épica; no entanto, não significa que se trata de uma mera reprodução desse gênero. Como se sabe, para se transmitir é necessário que um conceito passe por transformações. Nesse sentido, para reabilitar o gênero épico na literatura do século $\mathrm{XX}$, os autores africanos fizeram adaptações que correspondessem ao seu tempo e espaço.

Consabidamente, Corsino Fortes está entre aqueles que se engajaram no movimento da reabilitação da epopéia na contemporaneidade. Nascido em 1933, em Cabo Verde $^{1}$, o poeta tem uma vida profissional bastante diversificada: professor de ensino secundário; delegado do Ministério Público e Juiz de Direito, em Angola; ministro e secretário de Estado; embaixador em Portugal e noutros países; representante de Cabo Verde na comissão para o novo acordo ortográfico. Além disso, teve uma produção literária significativa, cujo principal objetivo foi expor suas idéias revolucionárias.

A atividade política e a intensa ligação com o povo cabo-verdiano influenciaram a obra de Fortes, que viu no gênero clássico a possibilidade de expressar suas angústias e expectativas em relação ao momento político, social e econômico da ilha de barlavento1. Todavia, como é previsível na épica moderna, o autor compõe um texto poético, ora resgatando, ora modificando, os pressupostos da epopéia.

Pão \& Fonema (1987), obra de maior notoriedade da bibliografia 'fortiana', integra o quadro da epopéia moderna. Trata-se do primeiro livro da trilogia A Cabeça Calva de Deus, que incorpora também Árvore \& Tambor e Pedras de Sol \& Substância. Nesse conjunto de poemas, o diálogo com a épica evidencia-se já na escolha da temática, pois o autor procura expressar a luta de afirmação do homem cabo-verdiano. Assim, semelhante aos escritores clássicos, Corsino Fortes requesta a nacionalidade como matéria central em sua obra.

Os três versos de NERUDA (1980), que iniciam a epopéia africana, revelam como Fortes teve a intenção de voltar-se para as questões nacionais. No fragmento a seguir é possível perceber como o poeta chileno retrata seu povo:

Aquí nadie se queda inmóvil.

Mi pueblo es movimiento.

Mi patria es un camino. (NERUDA apud FORTES, 1980, p.1)

Por que eleger essa obra para iniciar uma epopéia? Talvez a reposta para essa indagação esteja não somente no poema, mas também no autor, visto que Pablo Neruda esteve envolvido com as questões políticas do seu país. Embora esteja inserido em um espaço

\footnotetext{
${ }^{1}$ Cabo Verde é um conjunto de ilhas ao norte do Oceano Atlântico. O arquipélago é composto por dez ilhas que estão divididas em dois grupos: Barlavento e Sotavento.
} 
distinto, Neruda, assim como Fortes, participou ativamente do movimento político, lutando pelos interesses do povo chileno. De acordo com o crítico Mesquitela de Lima (1980, p.68) os versos de Neruda são bem significativos e dão uma visão do dinamismo interno de um poeta ligado a um povo por muito tempo acusado de indolente, mas que na verdade, se não “queda imóvel”, todo ele é movimento e a sua "pátria é um caminho".

No que concerne à questão formal, Pão \& Fonema segue parcialmente a estrutura da épica clássica. Trata-se de um longo poema narrativo, em que se expõe, em três cantos, as condições de vida e a expectativa do povo caboverdiano. Repara-se ainda que a intenção epicizante do autor confirma-se logo no princípio da obra, visto que nas páginas iniciais, encontra-se uma preposição:

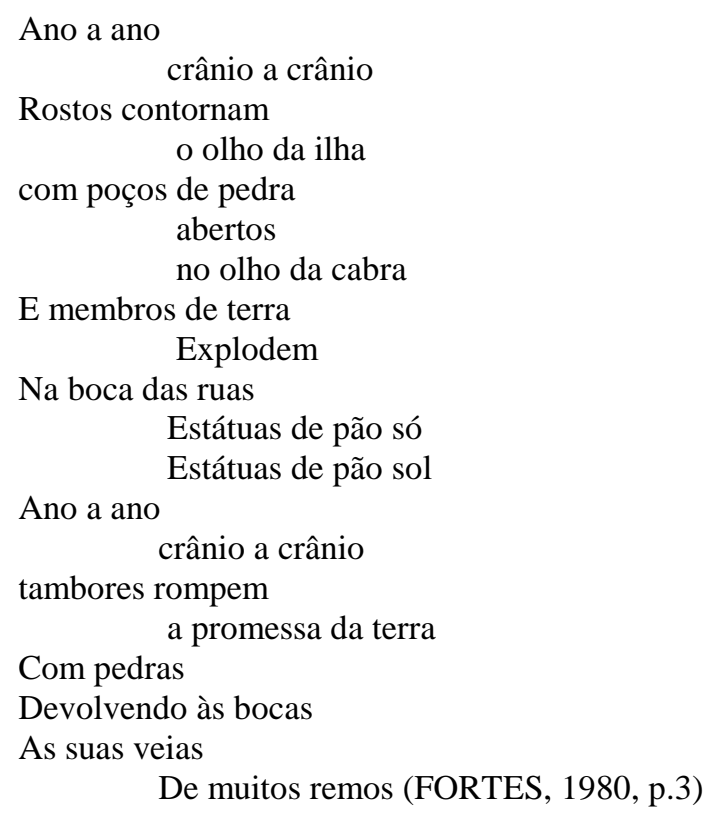

A proposição na obra de Corsino Fortes (1980), bem como na epopéia clássica, tem a função de apresentar o tema central do poema. Como observa Mesquitela Lima (1980, p.70), no estudo em que denomina Pão \& Fonema de "A Odisséia de um Povo", a estrutura interna da proposição oferece-nos toda a temática que Fortes deseja desenvolver. Nela vemos condensados os três cantos que se encadeiam numa dinâmica bem traçada.

As repetições dos primeiros versos, "ano a ano" e "crânio a crânio", representam a situação cíclica a que a população cabo-verdiana está submetida. A pobreza, o sofrimento e a opressão que assolam esse país a várias gerações ocupam posição de destaque no primeiro canto, intitulado "Tchon de pove tchon de pedra", que traduzido para o português significa "Chão de povo, chão de pedra". Em contrapartida, os tambores anunciam um futuro promissor em que a imobilidade do povo, antes visto como estátua, será substituída por uma 
luta eficaz contra a repressão. Essa proposição torna-se, portanto, um roteiro de Pão \& Fonema, visto que, através dela, o leitor é orientado a perceber as diferentes tonalidades que a obra adquire a cada canto.

Ora, seja por meio do tema ou da estrutura formal de Pão \& Fonema, Corsino Fortes (1980) se propõe a reabilitar o gênero épico. Entretanto, como já se mencionou, transmissão pressupõe transformação; conseqüentemente, a obra do escritor cabo-verdiano está imbuída de vários elementos que a torna distinta da epopéia tradicional, herdada da Antigüidade clássica.

Corsino Fortes (1980) insere em sua epopéia aspectos que são próprios da literatura do século XX. Além de empregar versos livres e assimétricos, o autor recorre ao recurso gráfico para aumentar a expressividade do poema.

No poema De boca a barlavento, que dá inicio ao primeiro canto, representa-se as condições de trabalho desumanas a que o homem cabo-verdiano é submetido. Nos primeiros versos, o eu-lírico lamenta a condição de seu corpo, calejado pela lavoura de milho. Todos os elementos evocados para construir essa imagem - "a minha mão de milho e marulho/ O deserto abocanhe a minha carne de homem/ E caranguejos devorem esta mão de semear" são dispostos num crescendo que culmina em:

Pela artéria do meu sangue que $g$

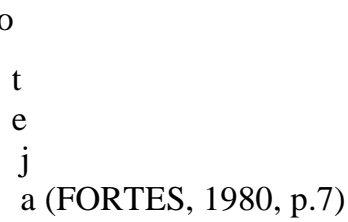

De fato, esse recurso gráfico aumenta a expressividade da dor, pois a palavra goteja cai em gotas como sangue do trabalhador. Não seria um contra-senso afirmar que esse artifício estilístico frustra o leitor que espera encontrar em Pão \& Fonema uma epopéia tradicional.

Outro fator que afasta a epopéia de FORTES (1980) do modelo clássico é o código lingüístico. O autor cabo-verdiano recusa, parcialmente, a língua do colonizador. Como se mencionou anteriormente, a literatura produzida no período da independência tinha como objetivo resgatar a cultura e, principalmente, a identidade dos povos africanos. Todavia, o autor do mundo colonizado, quando pretende fazer uma literatura nacional, tem uma difícil missão, já que precisa fazer um texto em língua ocidental, para veicular sua cultura.

Sabe-se que antes da chegada dos europeus, as sociedades africanas tinham outra forma de organizar o pensamento e a memória; privilegiava-se a oralidade em detrimento da escrita. Entretanto, os colonizadores introduziram a grafia das línguas européias, 
transformando o modo como os homens africanos contavam suas histórias. Na impossibilidade de regressar ao estado natural, já que estavam influenciados pela cultura européia, os escritores pós-revolucionários, inclusive Corsino Fortes, optam por construir um discurso, que agrupe a língua imposta por um processo histórico e os idiomas africanos.

Em Pão \& Fonema, o autor cabo-verdiano emprega dois instrumentos dialetais: o português e o crioulo de barlavento. Nesse sentido, apresenta-se para o leitor um texto híbrido e, sobretudo, um texto que não deseja esconder seu hibridismo. De fato, a ausência de glossário para elucidar os termos escritos em crioulo explicita a atitude de resistência do autor que desestrutura o modelo técnico-formal do colonizador, inserindo no mesmo patamar lingüístico ambos os dialetos.

Ora, se por um lado a atitude de resistência afasta a epopéia de Fortes do gênero clássico, por outro aproxima, pois quando relata o percurso de vida do povo da ilha de barlavento, o autor repete a mesma estrutura seguida por Dante Alighieri em A Divina Comédia. Na medida em que rememora o passado, relata as condições presentes e expõe as perspectivas para o futuro, o eu-lírico conduz o leitor de Pão \& Fonema a fazer uma excursão, cujo roteiro é composto por Inferno, Purgatório e Paraíso.

Nessa estrutura tripartite, o primeiro canto "Tchon de pove, tchon de pedra" equivale ao inferno. Os cinco poemas que o compõe abordam as vicissitudes presentes em barlavento, como fome, seca, pobreza, aculturação e, principalmente, a passividade da população mediante esses problemas.

Em primeiro lugar, o eu-lírico declara que o tema central do excerto infernal da epopéia são as dificuldades, fruto da situação geográfica e sócio-política de Cabo-Verde. No poema "De boca a barlavento" a arte está submetida ao sofrimento, pois "o sangue que goteja a árvore e o arbusto arrastam as vogais e os ditongos para dentro das violas, a fim de formar um poema com geometria de sangue" (FORTES, 1980, p.7). Em "Carta de Bia d'ideal" a população, que deveria esboçar alguma resistência, assiste ao espetáculo da miséria com "dor de cara contente". Como se não bastasse a atitude resignada do povo, muitos poetas ignoram suas raízes africanas, consequentemente, comportam-se como "negros greco-latinos"2.

O poema "Conto", terceiro integrante do inferno de Pão \& Fonema, concentra parte significativa dessas problemáticas:

$$
\begin{aligned}
& \text { Estavas estás } \\
& \text { Sem no } \\
& \text { Nas }
\end{aligned}
$$

\footnotetext{
${ }^{2} \mathrm{O}$ poeta faz referência mais especificamente a João Vário, poeta que segundo ele vive uma alienação cultural, impedindo a autenticidade e a luta dos cabo-verdianos.
} 


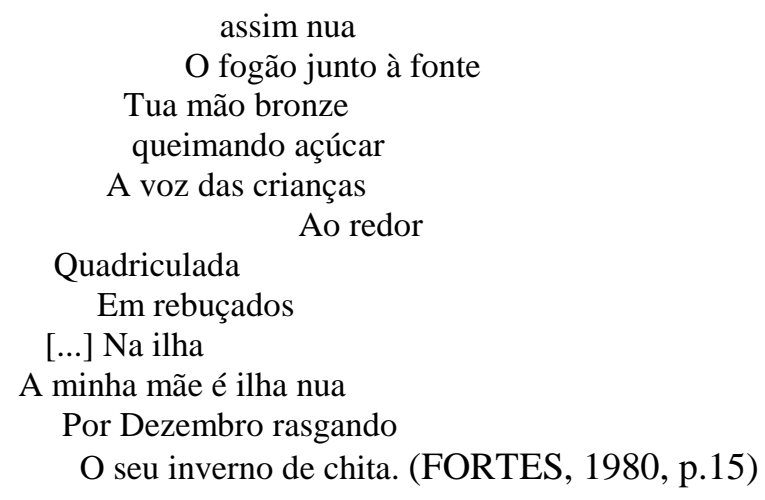

Nesses versos, o autor concilia a tradição épica com o prosaísmo moderno. A voz das crianças ou a mão que cozinha uniu-se à imagem da terra natal nua ou coberta apenas com chita, tecido módico incapaz aplacar o frio no inverno. Esse quadro remete, portanto, a imagem de uma nação desvalida "sem no na nos nas". Nos versos "estavas estás" (FORTES, 1980, p.15), o leitor nota que o desamparo não caracteriza somente o estado presente, pois os tempos verbais, pretérito imperfeito e presente do indicativo, denunciam a continuidade de um sofrimento que tem suas origens inscritas no passado.

O segundo canto, intitulado "Mar \& Matrimónio", corresponde à fase do purgatório. Nele, percebe-se um período de transitividade em que as vicissitudes ainda estão presentes, mas surgem expectativas positivas para o futuro. Os pés continuam nus, "nus de árvore nus de tambor" (FORTES, 1980, p.23); o eu-lírico, por sua vez, ainda que precise partir para garantir a subsistência, deixa sua marca na terra. Tal ação denuncia que as condições presentes obrigam partir, entretanto, o futuro possibilitará o regresso:

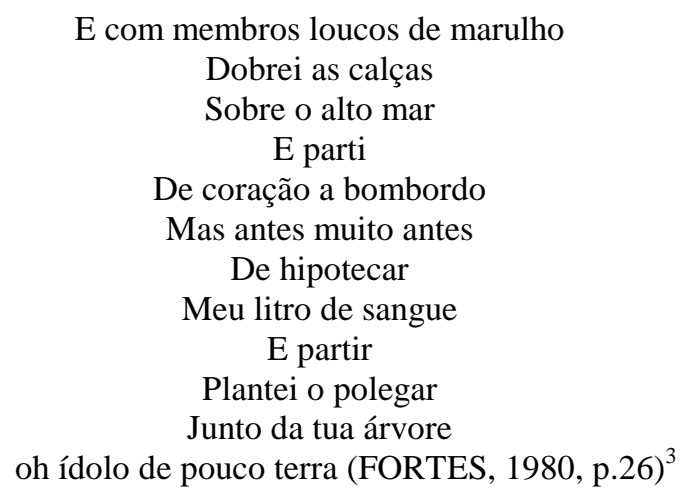

O drama do expatriado repete-se em outros poemas, como em "Emigrante"; nele, embora tenha o corpo peregrino coberto de sangue, o eu-lírico sabe que a sua voz será como onda de violão na praia e ajuntará a última fome à primeira. $\mathrm{O}$ quadro é completado pela dor da parturiente, indicando que "toda a partida é potência na morte e todo o regresso é infância

\footnotetext{
${ }^{3} \mathrm{O}$ poema permanece centralizado como em sua fonte de origem, a fim de manter a significação de sua distribuição.
} 
que soletra" (FORTES, 1980, p.40). Esses versos são a síntese da angústia e, concomitantemente, de um ar repleto de esperança. Desse modo, o purgatório configura-se como um estágio necessário em que a fome, o sofrimento e a angústia estão prestes a ser substituídos por um estado favorável.

O clima de euforia se intensifica no terceiro canto, cujo titulo é "Pão \& Património". O poema "Do nó de ser ao ónus de crescer" mostra que o leitor está preste a ingressar no paraíso:

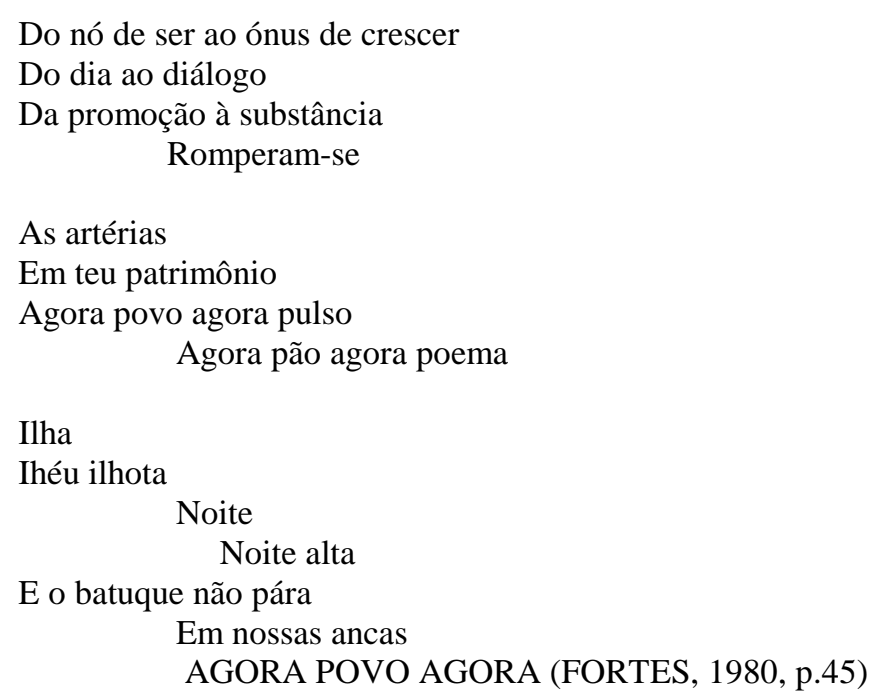

De acordo com Mesquitela de Lima (1980, p.85), para além da beleza fônica dos fonemas em sequiência, o conteúdo de "Do nó de ser ao ônus de crescer" é profundamente filosófico, pois trata-se do ser agrilhoado, amarrado a um nó de desfazer difícil, que se levanta e caminha para a libertação, através de sua própria ação. Por conseguinte, o povo, antes fraco e abatido, redescobre sua força, contribuindo para a mudança de estado: os pés nus dão lugar às ancas que se movem ao empolgante som do batuque; já o choro e a dor são substituídos por um cântico de alegria. No poema "De rosto a sotavento", nota-se ainda que as provações passadas tornaram-se as vitórias do presente, visto que a fome de ontem se converteu na fonte de hoje:

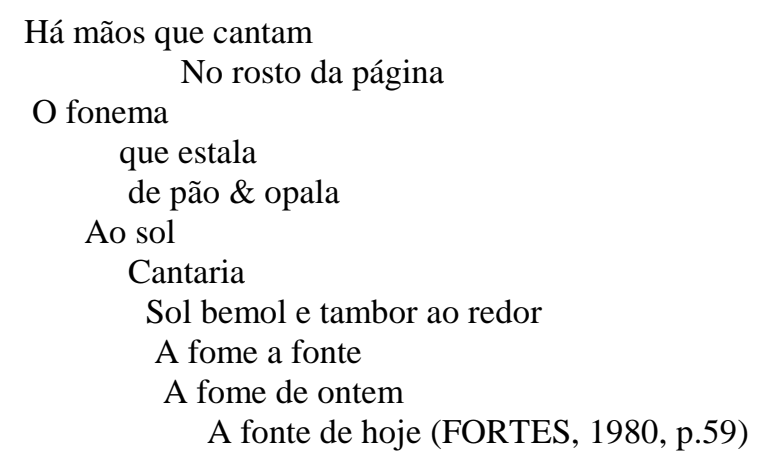


Ao final do terceiro canto o leitor percebe que transitou por três mundos diferentes, formados, principalmente, pela conciliação do gênero clássico e elementos da modernidade. Além de unir vertentes que a princípio parecem distintas, Corsino Fortes (1980) prova ser possível reabilitar a epopéia no século XX, pois, embora alguns teóricos afirmem que a épica é incompatível com a modernidade, Pão \& Fonema corrobora a idéia daqueles que crêem, assim como Florence Goyet (no prelo), que a epopéia é um gênero dinâmico por excelência, que problematiza as situações e os valores políticos.

\section{Considerações Finais}

Por que escolher as palavras Pão \& Fonema para intitular a epopéia cabo-verdiana? Em um país em que a seca prolongada já causou a morte de mais de 200 mil pessoas desde o início do século, a palavra pão representa, acima de tudo, a luta ferrenha do homem de barlavento para garantir a sobrevivência; nesse sentido, antes de ser um simples alimento, o pão é limite entre a vida e a morte. Existiria então termo mais apropriado para integrar o título dessa obra?

Fonema, por sua vez, explicita o desejo de livrar-se das marcas deixadas pelo colonizador. O trabalho lingüístico apurado do autor, que desliza do português padrão para o crioulo de barlavento, mostra a constante busca pela identidade.

A conciliação das palavras pão \& fonema traduz, portanto, uma atitude de resistência que se divide em duas vertentes que se completam: a luta pela vida e a luta pela vida livre e digna. Assim, reabilitar a epopéia na literatura africana do século XX não parece tarefa incoerente, visto que tanto os épicos clássicos como Corsino Fortes tratam de aspectos inerentes à condição humana que é a luta pela sobrevivência e a busca pela identidade.

\section{Referências}

FORTES, Corsino. Pão \& Fonema. Lisboa: Sá da Costa Editora, 1980.

MARIANO, Gabriel. Cultura Caboverdeana. Lisboa: Vega, 1991.

GOYET, Florence. L'épopée comme outil intellectuel. In NEIVA, Saulo. (Org.). Déclin \& confins de l'épopée au XIXe siécle. Clermont, (no prelo).

GOMES, Aldónio e CAVACAS, Fernanda. Dicionário de autores de literaturas africanas de lingua portuguesa. Lisboa: Caminho, 1997. 
LARANJEIRA, Pires. A Negritude Africana de Língua Portuguesa. Porto: Edições afrontamento, 1995.

LEITE, Ana Mafalda. A discursividade épica em Mayombe de Pepetela. In: FERREIRA, Manuel. (Org). Literaturas Africanas de Língua Portuguesa: Compilação das comunicações apresentadas durante o Colóquio sobre literatura dos países africanos de língua portuguesa. Lisboa: Fundação Calouste Gulbenkian, 1987, p.35-43.

LIMA, Mesquitela. Pão \& Fonema ou A Odisséia de um Povo. In Corsino, Fortes. Pão \& Fonema. Lisboa: Sá da Costa Editora, 1980, p.65-97. 